\title{
The psychosocial situation of obese children: Psychological factors and quality of life
}

\author{
U Korsten-Reck' \\ K Korsten' \\ K Haeberle' \\ K Kromeyer-Hauschild ${ }^{3}$ \\ H H Dickhuth' \\ E Schulz ${ }^{2}$ \\ 'Department of Rehabilitative \\ and Preventive Sports Medicine, \\ University Medical Center, University \\ of Freiburg, Freiburg, Germany; \\ ${ }^{2}$ Department of Child and Adolescent \\ Psychiatry, University of Freiburg, \\ Freiburg, Germany; ${ }^{3}$ nstitute of \\ Human Genetics and Anthropology, \\ Friedrich-Schiller-University Jena, Jena, \\ Germany
}

Correspondence: Ulrike Korsten-Reck Department of Rehabilitative and Preventive Sports Medicine, University Medical Center, University of Freiburg, 79106 Freiburg, Germany Tel +49 76I 2707477

Fax +497612707470

Email ulrike.korsten-reck@uniklinikfreiburg.de

\begin{abstract}
The psychosocial situation of obese children at the beginning of the Freiburg Intervention Trial for Obese Children (FITOC) program influences the course and outcome of intervention therapy. At the beginning of FITOC, mothers of 30 children (12 $\delta$ age $10.5 \pm 1.4$, 18 O; $10.2 \pm 1.3$ ) rated the psychopathological symptoms using the Child Behavior Checklist (CBCL) and the quality of life of their children (Inventar zur Erfassung der Lebensqualität [ILK]). $46.6 \%$ of mothers rated their children to be disturbed (normal population group, $2 \%$ disturbed). There was no correlation between the body mass index of the child and the CBCL score. On the ILK, the obese children themselves selected "good" while the mother's view of their childrens' quality of life varied around "poor". The stress on the mother increased with the degree of the child's obesity and number of critical life events $(p=0.030)$. The CBCL and the ILK at the beginning of treatment serve as a good screening instrument for psychopathology and distress in children with obesity.
\end{abstract}

Keywords: obesity, childhood, screening instruments, therapy

\section{Introduction}

In 1967, Staffieri and colleagues ${ }^{1}$ attributed negative qualities of character to obese people. In summary, he described them as lazy, inactive, stupid, ugly and sloppy. Similar comments were made in an Australian study. ${ }^{2}$ Moreover, with increasing age, the obese are even more subject to stigmatization. ${ }^{3}$ In western society, young girls who don't conform to this image of beauty, seem to suffer more during puberty than boys. ${ }^{4}$ Even children who are informed about the causes of obesity, generally prefer not to play with obese children. ${ }^{5}$ In one study, children, aged 8-11, were asked "which child do you like the most" when presented with pictures of handicapped children (on crutches, in a wheelchair, missing a hand, with a disfigured face or obese). The obese child ranked lowest. This was found in other studies independent of race, gender, socioeconomic status, surroundings and own handicaps. ${ }^{6}$ Although the prevalence and the degree of obesity in childhood have increased, reactions to obesity remain stereotypical. Therefore, a therapy program for obese children must set psychological as well as somatic goals.

The Freiburg Intervention Trial for Obese Children (FITOC) is an interdisciplinary, outpatient, obesity intervention program for obese children. The program consists of a combination of organized sports, behavioral therapy and nutritional advice and focuses on long-term behavior changes. Parental involvement is required. ${ }^{7,8}$ The program focuses on both weight reduction and psychological well-being. In this behavior therapy, techniques of behavior therapy are coupled which are based largely on principles of learning, specifically operant conditioning and respondent conditioning. This involves the process of learning to copy or to model the action of another through observing another in the children's group and in their families. In families, this plays a major role in changing habits. The therapist teaches cognitive strategies to cope with 
obesity to the children and their parents. The therapist might encourage children and parents to examine what they imagine happening when exposed to special stimuli like hunger, appetite, external stimuli such as smell and habits, emotional stimuli such as frustration and boredom, and social stimuli such as celebrations or parties. In the sport lessons, a token economy and behavioral activation is included.

We examined 30 obese children and their mothers at the beginning of the intervention program in order to summarize the psychosocial situation of these families, focus upon their needs, and better support them during therapy. With the Child Behavior Checklist (CBCL), the German instrument, Inventar zur Erfassung der Lebensqualität bei Kindern und Jugendlichen (ILK), and medical history, in which critical life events are mentioned, we investigated the psychosocial situation of the FITOC children and their mothers compared with a psychiatric group. With this knowledge it is possible to optimize therapy and predict the outcome.

\section{Method}

The $\mathrm{CBCL}^{9}$ was chosen as a screening instrument to categorize behavior and specific psychopathological symptoms. Average population groups in the USA and Germany were evaluated. Criterion validity was assessed and found to be acceptable, the range of test-retest value was 0.95 to 1.00 and of inter-rater reliability 0.93 to $0.96 .^{9}$ At the beginning of the program, 13 items pertaining to the CBCL were analyzed. On a scale of I-VII, the following items were quantified: social withdrawal, physical illness, fear-depression, social problems, schizoid-compulsive, attention disorders, antisocial behavior, aggressive behavior, and other problems (Table 1).
"Quality of life" was rated by the obese children themselves and independently by their mothers using ILK. ${ }^{10}$ The ILK is a 7-item questionnaire (scale 1-5 = very good-poor) used to estimate the wellness of children in various life situations. Two further items dealt with the stress of the actual illness and its treatment. The parents' version of the questionnaire included rating the child's quality of life. Two items for mothers assessed the personal stress caused by the illness and treatment of their children. Validity compared with other instruments investigating quality of life (KINDL) is in mid-range, test-retest reliability is $0.72 .^{11}$

At the time of this study there was no normal population group for the ILK so we compared our obese children with a same-age psychiatric cohort. The psychiatric counterparts with $n=39$ were patients in the psychiatric outpatient department of the clinic in Marburg (Kinder und Jugendpsychiatrie Marburg). Our results could be compared with the published data of the separate items. ${ }^{12}$ We also compared the responses of the mothers to those of their respective children.

Our FITOC reports include: pretreatment body mass index (BMI) values, pretreatment psychosocial factors, and the number (one or two) of critical life events. These critical life events were the separation or divorce of parents, death of members of their family, psychological stress, serious parental illness, or emigration. These findings were documented in the individual medical history of each child in the initial examination.

\section{Patients}

Twelve boys with an average age of $10.5 \pm 1.4$ and 18 girls aged $10.2 \pm 1.3$ were included in the analyses. Children

Table I Mothers' ratings of the emotionally disturbed behavior of their obese children in the CBCL (comparison with a normal population group, $\mathrm{n}=2856$ )

\begin{tabular}{|c|c|c|c|c|c|c|}
\hline $\begin{array}{l}\text { Symptom scale range (\%) } \\
\text { degree of disturbances scales }\end{array}$ & $\mathbf{n}$ & $-95 \%$ behavior normal & $\mathbf{n}$ & 95\%-98\% Low scores & $\mathbf{n}$ & $>98 \%$ Disturbed \\
\hline Total & II & $36.7 \%$ & 5 & $16.7 \%$ & 14 & $46.6 \%$ \\
\hline Internalization & II & $36.7 \%$ & 7 & $23.3 \%$ & 12 & $40.6 \%$ \\
\hline Externalization & 15 & $50.0 \%$ & 7 & $23.3 \%$ & 8 & $26.7 \%$ \\
\hline Social withdrawal & 23 & $76.6 \%$ & 3 & $10.0 \%$ & 4 & $13.3 \%$ \\
\hline Physical illness & 27 & $90.0 \%$ & - & - & 3 & $10.0 \%$ \\
\hline Fear-depression & 19 & $63.3 \%$ & 5 & $16.7 \%$ & 6 & $20.0 \%$ \\
\hline Social problems & 17 & $56.7 \%$ & 5 & $16.7 \%$ & 8 & $26.6 \%$ \\
\hline Schizoid-compulsive & 28 & $93.3 \%$ & 2 & $6.7 \%$ & - & - \\
\hline Attention disorders & 22 & $73.3 \%$ & 3 & $10.0 \%$ & 5 & $16.7 \%$ \\
\hline Antisocial behavior & 25 & $83.3 \%$ & 1 & $3.3 \%$ & 4 & $13.3 \%$ \\
\hline Aggressive behavior & 23 & $76.7 \%$ & I & $3.3 \%$ & 6 & $20.0 \%$ \\
\hline
\end{tabular}

Note: Frequencies of symptoms in \%. 
participating in the program were referred by family doctors, pediatricians, or school doctors. The program was open to the general public. Some of the children were outpatients at two university clinics (Universitäts-Kinderklinik, Kinder- und Jugendpsychiatrie der Universitätsklinik).

\section{Weight}

Body mass index was used as a basis for weight status. Except for one boy, all of the children had BMIs above the 97th percentile. 11 girls were above the 97th BMI-percentile, and 7 girls were between the 90th and 97th percentile, based on national reference data for German children. ${ }^{13}$ Children with a BMI between the 90th and 97th percentile were included in the program if they had somatic co-morbidities or one overweight parent. The psychiatric reference population $(n=39)$ came from the psychiatric outpatient clinic of the Department of Child and Adolescent Psychiatry, University of Marburg. Our data were compared with the published results derived from their child psychiatric population. ${ }^{12}$

\section{Pretreatment conditions}

Two thirds of the children $(n=20)$ had previously undergone various treatments, including speech therapy $(28.6 \%)$, remedial education (17.8\%), and play therapy. $36.7 \%$ of the mothers mentioned that their children had school problems.

More than $76.7 \%$ of the children $(n=23)$ had overcome one or more critical life event. These included separation or divorce of parents, death of family members, psychological stress, serious parental illness, or emigration.

\section{Reasons for being obese and taking part in this program}

The results of the questionnaires indicated that participants focused on nutritional behavior and ignored physical activity and psychological problems. $40 \%$ were motivated to take part because they were being mocked. $56.7 \%$ of the children had overcome more than one critical life event, $20 \%$ had overcome one, and $23.3 \%$ had no critical life event.

\section{Data analysis}

Mean values of important factors were determined through frequency distribution of individual case history samples. These were then evaluated and conclusions drawn regarding the psychosocial situation of the obese children.

Then normal distribution was identified using the Kolmogorov-Smirnov test.

T-tests were used to examine the homogenity of the cohort of obese children and their mothers followed by a two-factor variance analysis, which included the child's gender, age and whether parents were living together or not.

Furthermore, the influence of BMI on individual history data was tested (one-factor variance analysis, t-tests for dependent values and bivariate correlations). The test procedures were then evaluated.

For CBCL analysis, the special scales data were transformed into T-values. This was carried out by matching them with normal age and gender handbook values (6-11 and 12-18 years of age). Mean values were calculated from the T-values using the SPSS 10.0 program for windows (SPSS Inc., Chicago, IL, USA). The range of the percentage of obese children compared to normal children was determined based on these mean values. It was then possible to compare the respective percentage positions of obese versus randomly selected normal children on all competence and symptom scales and sub-scales in the table. The authors of the test agreed upon the degree of "disturbances".

Furthermore, all tests were correlated with individual history variables (BMI of the child and the mother, critical events in the life of the child). Questionnaires were correlated in the same manner.

Pearson correlations were calculated. For comparability of data from various sources, only z-transformed values were used. The homogeneity of t-test and variance was measured with the Levens test. Because this study was exploratory, no correction of the significance level was required. Statistical differences were drawn at a significance level of $\mathrm{p}=0.05$. The study was approved by the University of Freiburg Ethics Committee.

\section{Results}

The characteristics of the obese children examined are represented in Table 2. There are no significant gender differences.

\section{The psychopathological symptoms of obese children as rated by their mothers} Compared with the normal CBCL population group ( $2 \%$ disturbed), $46.6 \%$ of the mothers thought their children were disturbed, about $16.7 \%$ not very disturbed, and only $36.7 \%$ rated their children as being "normal". No gender differences were found (Table 1).

\section{Correlations with $\mathrm{BMI}, \mathrm{CBCL}$, and critical life events}

There was no correlation between the BMI of the child and the values rated by mothers in the CBCL. The more critical 
Table 2 Characteristics of the obese children examined

\begin{tabular}{llllll}
\hline & & N & Mean & SD & Median \\
\hline Age (yrs) & Boys & 12 & 10.459 & 1.401 & \\
& Girls & 18 & 10.145 & 1.269 & \\
BMI $\left(\mathrm{kg} / \mathrm{m}^{2}\right)$ & Boys & 12 & 26.9 & 3.1 & 26.0 \\
& Girls & 18 & 25.1 & 3.4 & 24.1 \\
BMI-SDS & Boys & 12 & 2.32 & 0.27 & \\
& Girls & 18 & 2.07 & 0.49 & \\
\hline
\end{tabular}

Note: Gender differences were not significant (chi square-Test; $p=0.964$ ).

life events they overcome, the higher the value was on the scale "internalization", "externalization", total score of symptoms, and "fear-depression" (Table 3).

\section{The quality of life as rated by the obese children themselves compared to their mothers}

On the ILK, the obese children (no gender differences were found) rated their total quality of life and special life situation as, "so far good", a significantly higher rating than that given by children in the psychiatric cohort (Table 4).

In contrast, mothers gave low ratings to the quality of life of their children in all life situations. Significant differences could be shown between mother and child in all categories except "family" and interests/leisure time activities (Table 5). No correlations were found between the mother's rating of the quality of her child's life and his/her BMI.

In the "specific disturbances" part of the questionnaire, mothers rated their child's stress due to obesity, diagnosis and therapy significantly higher than did the children themselves (Table 5).

\section{Correlations between BMI, ILK, and critical life events}

The higher the BMI of the child, the lower the child rated his/ her wellbeing in the family and his/her health situation. The numbers of critical life events correlated more closely with the child's rating than that of his/her mother. The mother's distress caused by her overweight child increased with the number of critical life events.

No significant correlations could be found between the quality of life (ILK) rated by the children and their mothers' ratings of psychopathological symptoms on the CBCL.

The higher the total score of the child's symptoms on the CBCL, the higher the mother rated the child's stress due to obesity and the lower the mother rated the quality of his/her child's life in the categories "family", "contacts with children of the same age", and "mental health".
Table 3 Correlations of CBCL scales with the BMI of the child and number (one or two) of critical life events (CLE)

\begin{tabular}{lll}
\hline CBCL & BMI r & CLE r \\
\hline Internalization & 0.22 & $0.47^{* *}$ \\
Externalization & 0.04 & $0.39^{*}$ \\
Total scores of symptoms & 0.10 & $0.43^{*}$ \\
Total competence & 0.33 & 0.11 \\
Social withdrawal & 0.24 & 0.29 \\
Physical illness & 0.21 & 0.24 \\
Fear-depression & 0.16 & $0.43^{*}$ \\
Social problems & 0.01 & 0.11 \\
Schizoid-compulsive & 0.04 & 0.12 \\
Attention disorders & 0.04 & 0.28 \\
Antisocial behavior & 0.03 & 0.15 \\
Aggressive behavior & 0.10 & 0.28 \\
Activities & 0.02 & 0.06 \\
Social competence & $0.45^{*}$ & 0.08 \\
School & 0.09 & 0.17 \\
\hline
\end{tabular}

Notes: Significance, $0.10 ; p>0.05 ; p \leq 0.05 ; *^{*} \leq 0.01 ; * * p \leq 0.001 ; * * *_{r}=$ Pearson coefficient of correlations.

\section{Sociodemographic parameters}

We found no significant differences in sociodemographic parameters such as gender, age, and socioeconomic background.

\section{Discussion}

The FITOC program focuses both on weight reduction and on psychological well-being of the investigated obese children. Therefore our intent was to analyze the behavior and symptomatology according to the CBCL for obese children at the beginning of the therapy program and to relate them to BMI and critical life events. On the CBCL, $46.6 \%$ of the mothers rated their children to be "disturbed", about $16.7 \%$ rated "low scores", and only $36.7 \%$ were "normal". In the categories "internalization", $41 \%$ of the children were disturbed, $23 \%$ with low scores, and in "externalisation", $27 \%$ were disturbed, and $23 \%$ had low scores. This is remarkable and demonstrates a high degree of psychopathology in our obese children. These findings are supported by studies that show that obese children have significantly fewer friends than normal-weight children. ${ }^{14}$ In one recent study, the quality of life of obese children and adolescents was significantly less than that of normal- weight children and, in their opinion, similar to children suffering from cancer. ${ }^{15}$ On the other hand, no social separation of same aged children was found. ${ }^{16}$ Some evidence exists that there is a correlation between social 
Table 4 Differences in rated quality of life in obese children compared to a psychiatric group

\begin{tabular}{llr}
\hline Life situations & $\begin{array}{c}\text { Obese children } \mathbf{n}=\mathbf{2 7} \\
\text { Mean } \pm \text { SD (95\% Cl) }\end{array}$ & $\begin{array}{l}\text { Patients } \mathbf{n}=39 \\
\mathbf{M e a n} \pm \mathbf{S D}(\mathbf{9 5} \% \mathbf{C l})\end{array}$ \\
\hline School & $1.85 \pm 0.77(1.79-1.91)$ & $2.26 \pm 1.01(2.21-2.31)$ \\
Family & $1.52 \pm 0.70(1.47-1.57)$ & $2.08 \pm 1.16(2.02-2.14)$ \\
Social contacts with same-age children & $1.67 \pm 0.88(1.61-1.73)$ & $2.26 \pm 1.09(2.21-2.31)$ \\
Interests/leisure time & $1.85 \pm 1.10(1.77-1.93)$ & $2.64 \pm 1.41(2.57-2.71)$ \\
Physical health & $1.37 \pm 0.63(1.32-1.42)$ & $2.23 \pm 1.31(2.16-2.30)$ \\
Mental health & $1.89 \pm 0.70(1.84-1.94)$ & $2.41 \pm 1.04(2.36-2.46)$ \\
Total quality of life & $1.52 \pm 0.70(1.47-1.57)$ & $2.10 \pm 0.88(2.06-2.14)$ \\
Suffering from illness & $2.44 \pm 1.19(2.35-2.53)$ & $2.79 \pm 0.99(2.74-2.84)$ \\
Suffering under diagnosis/therapy & $1.59 \pm 0.84(1.53-1.65)$ & $2.29 \pm 1.04(2.24-2.34)$ \\
\hline
\end{tabular}

Notes: Scales I-5: I = very well, 2 = okay; 3 = quite well, 4 = bad; 5 = very bad; $95 \% \mathrm{Cl}, 95 \%$ confidence interval.

discrimination in childhood and psychological crises in later life. ${ }^{17}$ Differentiated data in the literature indicate that there is no correlation between obesity and self-esteem ${ }^{18}$ but also that the higher the weight, the lower the self-esteem. ${ }^{14,16}$ A lack of self-esteem in obese adolescents has not generally been observed. ${ }^{14,19}$ In their mother's opinion, the children participating in the FITOC program were very obese and stressed by obesity. This could be due to the mothers' knowledge about the following diseases of being obese or due to the mothers connecting obesity with other problems existing in their families. Mothers of obese children often suffer from the negative image of obesity in society, while their children don't see themselves as being disturbed when in a group with other obese children.

Only a few studies have investigated the quality of life of obese children. Compared with children with psychiatric disorders, on average, obese children gave themselves higher "quality of life" ratings.

Braet and colleagues ${ }^{20}$ compared one group of obese children in an outpatient and inpatient setting with

Table 5 Comparison of perspectives: Estimation of "the quality of life" by the obese child and his/her mother with correlations between BMI and numbers of critical life events (CLE)

\begin{tabular}{|c|c|c|c|c|c|c|}
\hline $\begin{array}{l}\text { Categories of quality of life } \\
\mathbf{N}=\mathbf{3 0}\end{array}$ & $\begin{array}{l}\text { Children themselves } \\
\text { Mean } \pm \text { SD }(95 \% \mathrm{Cl})\end{array}$ & $\begin{array}{l}\text { Mothers' rating of their child } \\
\text { Mean } \pm \text { SD }(95 \% \mathrm{Cl})\end{array}$ & $\begin{array}{l}\text { Children's } \\
\text { CLE R }\end{array}$ & $\begin{array}{l}\text { Mothers' } \\
\text { CLE R }\end{array}$ & $\begin{array}{l}\text { Children's } \\
\text { Bmi R }\end{array}$ & $\begin{array}{l}\text { Mothers' } \\
\text { Bmi R }\end{array}$ \\
\hline School & $1.87 \pm 0.78(1.82-1.92)$ & $2.33 \pm 0.84(2.28-2.38)$ & 0.06 & 0.02 & 0.33 & 0.07 \\
\hline Family & $1.60 \pm 0.72(1.55-1.65)$ & $1.73 \pm 0.64(1.69-1.77)$ & 0.17 & 0.30 & $0.34 *$ & 0.03 \\
\hline Social contacts with same aged & $1.63 \pm 0.85(1.57-1.69)$ & $2.13 \pm 0.86(2.07-2.19)$ & 0.14 & 0.31 & 0.25 & 0.04 \\
\hline Interests/ leisure time activities & $1.97 \pm 1.13(1.90-2.04)$ & $2.17 \pm 0.87(2.11-2.23)$ & 0.14 & 0.13 & 0.06 & 0.21 \\
\hline Physical health & $1.43 \pm 0.68(1.39-1.47)$ & $2.07 \pm 0.69(2.02-2.12)$ & 0.26 & $0.38 *$ & $0.39 *$ & 0.27 \\
\hline Psychological health & $1.90 \pm 0.66(1.86-1.94)$ & $2.67 \pm 0.84(2.62-2.72)$ & 0.07 & $0.47 * *$ & 0.22 & 0.21 \\
\hline Total quality of life & $1.57 \pm 0.73(1.52-1.62)$ & $2.30 \pm 0.70(2.25-2.35)$ & 0.03 & $0.54 * *$ & 0.07 & 0.01 \\
\hline Stress by obesity & $2.40 \pm 1.16(2.32-2.48)$ & $2.97 \pm 0.8 \mathrm{I}(2.92-3.02)$ & 0.25 & 0.00 & 0.09 & 0.19 \\
\hline Stress by diagnostic/ therapy & $1.60 \pm 0.86(1.54-1.66)$ & $2.50 \pm 1.11(2.43-2.57)$ & 0.02 & 0.30 & 0.14 & 0.05 \\
\hline $\begin{array}{l}\text { Stress of mothers by obesity of } \\
\text { their child (mothers' rating) }\end{array}$ & $2.40 \pm 1.16(2.32-2.48)$ & $3.20 \pm 0.81(3.15-3.25)$ & - & $0.40 *$ & $1 /$ & 0.28 \\
\hline
\end{tabular}

Notes: Significance, 0.10; $>0.05 ; \mathrm{p} \leq 0.05 ; *_{\mathrm{p}} \leq 0.01 ; *^{*} \mathrm{p} \leq 0.00 \mathrm{I} ; *^{* * *} \mathrm{r}=$ Pearson coefficient of correlations; $95 \% \mathrm{Cl}, 95 \%$ confidence interval. 
normal-weight children and found that self-esteem was lower in both obese groups, but that psychiatric symptoms could only be found in the inpatient setting. The conclusion was that psychiatric symptomatology was rated as being a greater problem than obesity. An obese child can become suicidal when teased or mobbed by his/her family or other social groups. ${ }^{21}$ Goodman ${ }^{22}$ did not find the obese child to be more depressed than the average child. But this may depend on how the results were assessed. Faith and Friedmann ${ }^{23,24}$ have described such methods. Moreover, even normal-weight children are often dissatisfied with their body weight because of the "thin is beautiful" image. ${ }^{25}$ It could be demonstrated that levels of self-esteem are much the same in obese and normal-weight children. A significant difference was only found if obesity persisted for four years or longer, ${ }^{14}$ which was found in the FITOC group.

The FITOC children gave themselves significantly higher wellbeing ratings than did the psychiatric group (Marburg). Perhaps the FITOC children stand to gain from a group feeling, build over the first weeks of therapy and acceptance by therapists and thus hold more positive opinions of their own situations, while in their mothers rated the quality of life of their children lower by knowing all negative psychological and somatic consequences of obesity.

We must recognize that depression or fear of gaining weight can lead to behavioral changes. ${ }^{22,26}$ The FITOC children rated their wellbeing within the family. The higher the BMI, the unhappier they were. In Western society, obesity has negative associations. Teasing increases dissatisfaction with a "fat" body image and this can lead to other eating disorders. $^{27}$

We found, that the more critical life events experienced by the children, the lower their mothers rated their child's level of physical health, mental health and total quality of life. ${ }^{28}$

Obesity and critical life events are often associated in families treated in the FITOC program. These families show a low socioeconomic background with critical life events like unemployment or divorces of the parents. Interestingly we found no correlations between the mothers' BMI values and other values (Table 5). But possibly in mother's medical history obesity in childhood exists.

The limitations of the study are the small sample size, lack of availability of after-treatment results, and the absence of an obese control group investigated by the same instruments. These are initial results of quality of life in an obese cohort. This study was not to evaluate screening instruments, but to get an individual profile of every child obesity-optimizing therapy and children's wellbeing.

\section{Conclusion}

The CBCL and the ILK are two questionnaires which fit well into the FITOC intervention program because they facilitate analysis of the psychopathological symptoms and co-morbidities of the obese children taking part in the program. Screening with CBCL enables the treating physician to optimize FITOC intervention. Our data support evidence that $46.6 \%$ of the FITOC group need additional psychotherapeutic and family-based interventions.

\section{Disclosure}

The authors declare no conflicts of interest in this work.

\section{References}

1. Staffieri JR. A study of social stereotype of body image in children. JPers Soc Psychol. 1967;7:101-104.

2. Tiggemann M, Wilson-Barrett E. Children's figure ratings: relationship to self-esteem and negative stereotyping. Int $J$ Eat Disord. 1998;23:83-88.

3. Brylinsky JA, Moore JC. The identification of body build stereotypes in young children. $J$ Res Personal. 1994;28:170-181.

4. Falkner NH, Neumark-Sztainer D, Story M, Jeffery RW, Beuhring T, Resnick MD. Social, educational, and psychological correlates of weight status in adolescents. Obes Res. 2001;9:32-42.

5. Bell SK, Morgan SB. Children's attitudes and behavioral intentions toward a peer presented as obese: does a medical explanation for the obesity make a difference? J Pediatr Psychol. 2000;25:137-145.

6. Latner JD, Stunkard AJ. Getting worse: the stigmatization of obese children. Obes Res. 2003;11:452-456.

7. Korsten-Reck U, Kromeyer-Hauschild K, Wolfarth B, Dickhuth HH, Berg A. Freiburg Intervention Trial for Obese Children (FITOC): results of a clinical observation study. Int J Obes Relat Metab Disord. 29:356-361.

8. Korsten-Reck U, Rudloff C, Kayser R, et al. [Freiburg intervention program for ambulatory therapy of obesity in childhood (FITOC)]. Versicherungsmedizin. 2002;54:21-25.

9. Döfpner M, Plück J, Bölte S, Lenz K, Melchers P, Heim K. Elternfragebogen über das verhalten von Kindern und Jugendlichen: Deutsche Bearbeitung der Child Behavior Checklist (CBCL). Köln: Arbeitsgruppe Kinder-, Jungend-, und Familiendiagnostik;1998.

10. Mattejat F, Jungmann J, Meusers M, et al. [An inventory for assessing the quality of life of children and adolescents - a pilot study] Z Kinder Jugendpsychiatr Psychother. 1998;26:174-182.

11. Ravens-Sieberer U, Bullinger M. Assessing health-related quality of life in chronically ill children with the German KINDL: first psychometric and content analytical results. Qual Life Res. 1998;7:399-407.

12. Mattejat F, Remschmidt H. Zur erfassung der Lebensqualität bei psychisch gestörten Kindern und Jugendlichen: Eine Übersicht. Zeitschrift für Kinder- und Jugendpsychatrie; 1998. p. 183-196.

13. Kromeyer-Hauschild K, Wabitsch M, Kunze D, et al. Perzentile für den Body-mass-Index für das Kindes- und Jugendalter unter Heranziehung verschiedener deutscher Stichproben. Monatsschr Kinderheilkd. 2001;149:807-818.

14. Strauss RS. Childhood obesity and self-esteem. Pediatrics. 2000;105:e15.

15. Schwimmer JB, Burwinkle TM, Varni JW. Health-related quality of life of severely obese children and adolescents. JAMA. 2003;289: 1813-1819.

16. Phillips RG, Hill AJ. Fat, plain, but not friendless: self-esteem and peer acceptance of obese pre-adolescent girls. Int J Obes Relat Metab Disord. 1998;22:287-293. 
17. Bagwell CL, Newcomb AF, Bukowski WM. Preadolescent friendship and peer rejection as predictors of adult adjustment. Child Dev. 1998;69:140-153.

18. French SA, Story M, Perry CL. Self-esteem and obesity in children and adolescents: a literature review. Obes Res. 1995;3:479-490.

19. French SA, Perry CL, Leon GR, Fulkerson JA. Self-esteem and change in body mass index over 3 years in a cohort of adolescents. Obes Res. 1996;4:27-33.

20. Braet C, Mervielde I, Vandereycken W. Psychological aspects of childhood obesity: a controlled study in a clinical and nonclinical sample. J Pediatr Psychol. 1997;22:59-71.

21. Eisenberg ME, Neumark-Sztainer D, Story M. Associations of weightbased teasing and emotional well-being among adolescents. Arch Pediatr Adolesc Med. 2003;157:733-738.

22. Goodman E, Whitaker RC. A prospective study of the role of depression in the development and persistence of adolescent obesity. Pediatrics. 2002;110:497-504.
23. Faith MS, Matz PE, Jorge MA. Obesity-depression associations in the population. J Psychosom Res. 2002;53:935-942.

24. Friedman MA, Brownell KD. Psychological correlates of obesity: moving to the next research generation. Psychol Bull. 1995;117:3-20.

25. Robinson TN, Chang JY, Haydel KF, Killen JD. Overweight concerns and body dissatisfaction among third-grade children: the impacts of ethnicity and socioeconomic status. J Pediatr. 2001;138:181-187.

26. Richardson LP, Davis R, Poulton R, et al. A longitudinal evaluation of adolescent depression and adult obesity. Arch Pediatr Adolesc Med. 2003;157:739-745.

27. Brown TA, Cash TF, Lewis RJ. Body-image disturbances in adolescent female binge-purgers: a brief report of the results of a national survey in the USA. J Child Psychol Psychiatry. 1989;30:605-613.

28. Hill AJ, Lissau I. Psychological Factors. In: Burniat W, Cole TJ, Lissau I, Poskitt EM, editors. Child and Adolescent Obesity. Causes and Consequences; Prevention and Management. Cambridge: Cambridge University Press; 2002. pp. 109-127. 
